\title{
Prognostic Value of Soluble Suppression of Tumorigenicity 2 in Chronic Kidney Disease Patients: A Meta-Analysis
}

\author{
Guangying Guo $\mathbb{D}^{D}$, Aoran Huang $\mathbb{D}$, Xin Huang $(\mathbb{D}$, Tianhua Xu $\mathbb{D}$, and Li Yao $\mathbb{D}$ \\ Department of Nephrology, The First Hospital of China Medical University, 155 North Nanjing Street, Heping District, \\ Shenyang 110000, China \\ Correspondence should be addressed to Li Yao; liyao_cmu@163.com
}

Received 27 August 2020; Revised 31 December 2020; Accepted 14 January 2021; Published 27 January 2021

Academic Editor: Peng fei Li

Copyright @ 2021 Guangying Guo et al. This is an open access article distributed under the Creative Commons Attribution License, which permits unrestricted use, distribution, and reproduction in any medium, provided the original work is properly cited.

\begin{abstract}
Objective. Previous studies have controversial results about the prognostic role of soluble suppression of tumorigenicity 2 (sST2) in chronic kidney disease (CKD). Therefore, we conduct this meta-analysis to access the association between sST2 and all-cause mortality, cardiovascular disease (CVD) mortality, and CVD events in patients with CKD. Methods. The publication studies on the association of sST2 with all-cause mortality, CVD mortality, and CVD events from PubMed and Embase were searched through August 2020. We pooled the hazard ratio (HR) comparing high versus low levels of sST2 and subgroup analysis based on treatment, continent, and diabetes mellitus (DM) proportion, and sample size was also performed. Results. There were 15 eligible studies with 11,063 CKD patients that were included in our meta-analysis. Elevated level of sST2 was associated with increased risk of all-cause mortality (HR 2.05; 95\% confidence interval (CI), 1.51-2.78), CVD mortality (HR 1.68; 95\% CI, 1.352.09), total CVD events (HR 1.88; 95\% CI, 1.26-2.80), and HF (HR 1.35; 95\% CI, 1.11-1.64). Subgroup analysis based on continent, DM percentage, and sample size showed that these factors did not influence the prognostic role of sST2 levels to allcause mortality. Conclusions. Our results show that high levels of sST2 could predict the all-cause mortality, CVD mortality, and CVD events in CKD patients.
\end{abstract}

\section{Introduction}

Chronic kidney disease $(\mathrm{CKD})$ results in great health burden with an approximate incidence rate of $9.1 \%$ worldwide. Especially in countries of low and middle income, the incidence rate of CKD is up to $14.1 \%[1,2]$. CKD not only has a huge effect on global health but also acts as an important risk factor for cardiovascular disease (CVD) which accounts for approximately $40 \% \sim 50 \%$ of deaths in adults when CKD progresses into end stage renal disease (ESRD) $[1,3]$. Therefore, it is urgent to find biomarkers that could help identifying high-risk CKD patients and predicting the risk of mortality and CVD in CKD patients.

Suppression of tumorigenicity 2 (ST2) is a member of the interleukin-1 (IL-1) receptor family produced by various types of tissues and cells in response to inflammation, stress, and other triggers $[4,5]$. There are two essential isoforms for ST2: a membrane linked form ST2L and a soluble form sST2 [6]. ST2L plays an important role in protecting heart muscle tissue from apoptosis, fibrosis, and cardiomyocyte hypertrophy through interaction with IL-33 which is a member of IL1 cytokine family and a key ligand that binds to ST2L. In contrast, the SST2 decreases the cardioprotective effects of ST2L by competitively binding to IL-33 $[4,6]$. Recent studies have evaluated SST2 as a prognosis marker in CKD patients independently of the renal function, age, and dialysis process, unlike other cardiac biomarkers $[7,8]$. Wang et al. compared the role of sST2 with $\mathrm{N}$-terminal probrain natriuretic peptide (NT-proBNP), a classical prognostic biomarker in CKD, on predicting both all-cause and cardiovascular mortality among maintenance hemodialysis (MHD) patients and found the superior role of sST2 [9]. However, another study found that sST2 alone did not predict prognosis and/or CVD events in nondialyzed CKD patients [8]. Therefore, a meta-analysis is required to systematically evaluate the prognostic value of sST2 in CKD patients.

The individual studies may have limitation to obtain a definitive conclusion. Considering the inconsistent results 
between the sST2 and adverse clinical outcomes, we conduct a meta-analysis by combining the results from all available studies to (1) evaluate the prognosis value of sST2 in CKD patients, (2) explore the potential between-study heterogeneity, and (3) investigate the potential publication bias.

\section{Materials and Methods}

2.1. Literature Search Strategy. Our meta-analysis was performed and reported according to the Preferred Reporting Items for Systematic Reviews and Meta-Analyses (PRISMA) statement [10]. We searched the literatures in PubMed and Excerpta Medica Database (Embase) from inception to 9 August 2020. The search strategy included a combination of the following keywords: (chronic kidney failure OR chronic renal failure OR chronic renal insufficiency OR chronic renal insufficiencies OR chronic kidney insufficiency OR chronic kidney insufficiencies OR chronic kidney disease OR chronic kidney diseases OR chronic renal disease OR chronic renal diseases OR end stage renal disease OR endstage renal disease OR end stage kidney disease OR endstage kidney disease OR end-stage renal failure OR dialysis OR renal dialyses OR hemodialysis OR hemodialyses OR extracorporeal dialyses OR kidney transplantation OR kidney transplantations OR renal transplantation OR renal transplantations OR kidney grafting) AND (ST2 OR sST2 OR suppression of tumorigenicity 2 OR interleukin 1 receptor like 1 protein). Moreover, we also reviewed the reference lists of all retrieved relevant articles and reviews to identify additional relevant studies that were not captured by our database searches.

2.2. Study Selection. Studies were included in present quantitative analysis if they meet the following criteria: (1) cohort studies (including prospective or retrospective designs); (2) the diagnostic criteria for CKD are based on definitions of the Kidney Disease Improving Global Outcomes (KDIGO) 2017 clinical practice guidelines [11]. (3) sST2 concentration at baseline was measured and provided the hazard ratio (HR) and the corresponding 95\% confidence interval (CI) for sST2 concentration and adverse clinical outcomes and (4) reported at least one specific CVD events, such as CVD mortality, total CVD events, dysrhythmia, and heart failure (HF) or all-cause mortality using multivariable-adjusted risk evaluation. The following exclusion criteria were also used: (1) case reports, editorials, letters, or review articles; (2) patients were pregnant women or $<18$ years; and (3) HR or the corresponding 95\% CI were not available. If data was duplicated in more than one study, we included the most recent one published. There were no restrictions on gender, race, CKD stage (including predialysis patients and those with ESRD who are receiving dialysis or functioning renal transplantations), or language of the studies.

To ensure the correct selection according to the inclusion criteria, two researchers (GGY and HAR) selected the articles and reviewed all possible studies independently. If the eligibility of a study was controversial between them, it was resolved by consulting the third researcher (HX).
2.3. Data Extraction and Quality Assessment. The following data from each study was extracted independently by two researchers (GGY and HAR) from the full text: the first author's name, publication year, study type, study location, participants characteristics (number, mean/median age at baseline, sex composition), duration of follow-up, the proportion of diabetes mellitus (DM) and hypertension, levels of serum/plasma sST2, main end point, and multivariableadjusted HR (95\% CI).

To evaluate the risk of bias and the quality of eligible studies, the Newcastle-Ottawa Scale (NOS) was used by two researchers (GGY and HAR) independently [12]. This scale included items related to selection of participants, comparability of study design and analysis, inclusion and exclusion criteria at baseline, follow-up years, confounding adjustment on the multivariate analysis, and outcome ascertainment. The accumulated scores categorized studies into 6-9 points or less than 6 points.

2.4. Data Analysis and Statistical Methods. The pooled adjusted HRs with 95\% CIs were calculated to evaluate the strength of the association between sST2 levels and adverse outcomes in CKD patients. The Higgins' $I^{2}$ statistic was further used to evaluate the heterogeneity of the studies. The included studies were considered as having low likelihood of heterogeneity when $I^{2}<50 \%$. The fix-effects model was used if there is no significant heterogeneity among included studies; otherwise, the random-effects model was used. The publication bias was evaluated by using Begg's and Egger's test. Subgroup analysis and meta-regression on potential sources of heterogeneity of studies such as stage of kidney disease were also performed. The statistical analyses were done using STATA 12 (Stata Corp, College Station, TX, USA) $(p<0.05)$.

\section{Results}

3.1. Literature Search and Characteristics of Selected Studies. A total of 107 studies from PubMed, 117 studies from Embase, and two studies from the reference lists were identified initially up to August 2020. After exclusion of duplicate and nonrelevant studies, 25 studies were reviewed in full text. Another ten studies were excluded for other reasons (Figure 1), and fifteen studies met our inclusion criteria and were finally included in the meta-analysis [8, 9, 13-25].

Among the 15 studies, eight studies specifically reported dialysis patients $[9,13,14,17-19,22,24]$, five studies specifically reported predialysis $[8,15,20,21,23]$, and two studies specifically reported kidney transplant patients $[16,25]$. The main characteristics are summarized in Table 1 . The concentration of sST2 was determined in plasma/serum by EnzymeLinked Immunosorbent Assay (ELISA) method in almost all studies except for one using proteomics. Study individuals ranged from 74 to 3,314 with a total of 11,063 , and the mean or median follow-up years ranged from 1.7 to 16.2. Six studies were conducted in European countries [8, 13, 15, 18, 22, 25], five from Asian countries [9, 14, 17, 19, 24], and the other four were carried out in America $[16,20,21,23]$. In 


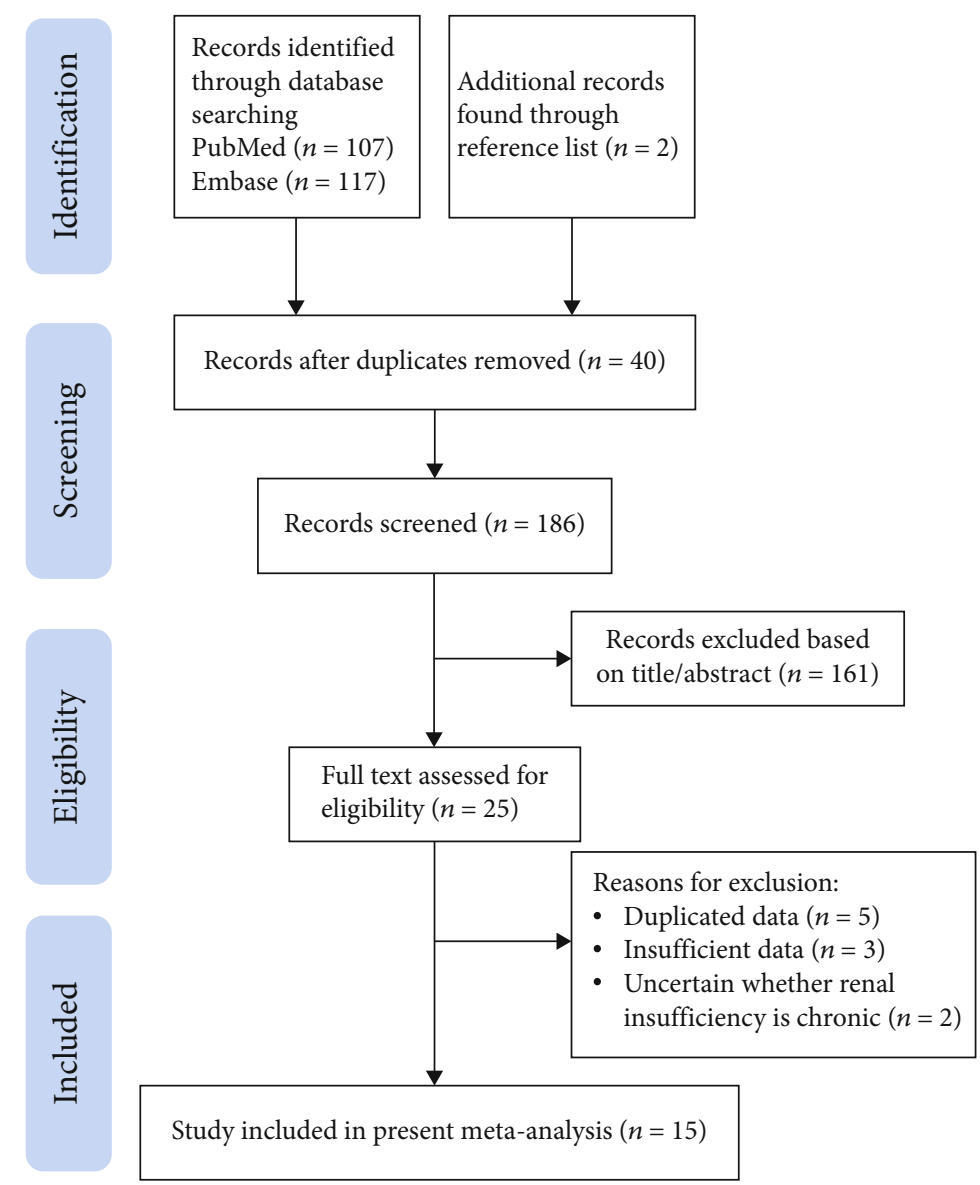

FIgURE 1: Flow diagram of the search strategy.

addition, the quality of five studies was high, and another ten studies was moderate (Table 2).

3.2. sST2 and All-Cause Mortality in CKD Patients. Nine studies evaluated the prognostic value of sST2 for all-cause mortality $[9,13,14,17-20,24,25]$. Among the nine studies, sensitivity analysis showed results from Wang et al. [9] that contributed great heterogeneity to both all-cause mortality and CVD mortality. Meta-analysis of the remaining eight studies showed increased sST2 level that was positively associated with increased all-cause mortality (HR: 2.05; 95\% CI: $1.51-2.78 ; p<0.001$; Figure 2) with heterogeneity $\left(I^{2}\right.$ : $\left.81.6 \%, p_{\text {het }} \leq 0.001\right)$ in CKD patients.

We also conducted subgroup analysis based on treatment, continent, DM percentage, and sample size. The subgroup analysis based on treatment showed that high sST2 levels could predict all-cause mortality in each subgroup (HR for dialysis: 2.72; 95\% CI: 1.65-4.49; HR for predialysis: 1.41; 95\% CI: 1.22-1.63; HR for transplant patients: $1.36 ; 95 \%$ CI: 1.00-1.85; Table 3). The subgroup analysis based on continent, DM percentage, and sample size showed that these factors did not influence the prognostic role of sST2 levels to all-cause mortality (Table 3 ).

3.3. sST2 and CVD Mortality in CKD Patients. Five studies evaluated the prognostic value of $\mathrm{sST} 2$ for CVD mortality
$[9,17,19,22,25]$. Meta-analysis of these studies showed high sST2 levels increased the risk of CVD mortality in CKD patients with a pooled HR of 1.68 (95\% CI: 1.35-2.09; $p<$ 0.001 ; Figure $3(\mathrm{a}))$ without significant heterogeneity $\left(I^{2}\right.$ : $\left.31.6 \%, p_{\text {het }}=0.223\right)$. In subgroup analysis based on continent, high sST2 levels increased the risk of CVD mortality by $45 \%$ (HR: $1.45 ; 95 \%$ CI: $1.08-1.96 ; p=0.014 ; I^{2}: 9.7 \%$, $p_{\text {het }}=0.293$; Figure $\left.3(\mathrm{~b})\right)$ for CKD patients in Europe and America. More significantly, high sST2 levels increased risk of CVD mortality for CKD patients in Asia by 99\% (HR: 1.99; 95\% CI: $1.45-2.74 ; p<0.001 ; I^{2}: 23.5 \%$, $p_{\text {het }}=0.253$; Figure 3(b)).

3.4. sST2 and CVD Events in CKD Patients. Nine studies evaluated the prognostic value of sST2 for total CVD events [8, $13-16,19,20,24,25]$. When pooling data of total CVD events, we found that high sST2 levels increased the risk of total CVD events (HR: 1.88; 95\% CI: 1.26-2.80; $p=0.002$; Figure $4(\mathrm{a}))$ with heterogeneity $\left(I^{2}: 89.5 \%, p \leq 0.001\right)$ in CKD patients.

Subsequently, we performed subgroup analysis based on treatment, continent, DM percentage, and sample size. The subgroup analysis based on treatment showed that high sST2 levels could predict total CVD events among dialysis patients (HR: 3.43; 95\% CI: 1.43-8.24; Table 4) 
TABLE 1: Baseline characteristics of included studies.

\begin{tabular}{|c|c|c|c|c|c|c|c|c|c|c|c|}
\hline Author year & Country & $\begin{array}{c}\text { Study } \\
\text { population }\end{array}$ & $\begin{array}{l}\text { Subjects } \\
\quad(n)\end{array}$ & $\begin{array}{c}\text { Male } \\
(\%)\end{array}$ & $\begin{array}{l}\mathrm{DM} \\
(\%)\end{array}$ & $\begin{array}{c}\mathrm{HTN} \\
(\%)\end{array}$ & $\begin{array}{l}\text { CVD } \\
(\%)\end{array}$ & Age (year) & $\begin{array}{l}\text { Follow-up } \\
\quad \text { (year) }\end{array}$ & $\begin{array}{c}\mathrm{ST} 2 \\
(\mathrm{ng} / \mathrm{mL})\end{array}$ & $\begin{array}{c}\text { End-point } \\
\text { event }\end{array}$ \\
\hline Hammer 2015 & Germany & HD & 1196 & $54.0 \%$ & $100.0 \%$ & NA & NA & $66.0 \pm 8.3$ & 4.0 & $\begin{array}{c}25.0 \\
\text { (median) }\end{array}$ & $\begin{array}{c}\text { All-cause } \\
\text { mortality } \\
\text { Total CVD } \\
\text { events }\end{array}$ \\
\hline Obokata 2016 & Japan & $\mathrm{HD}$ & 423 & $68.8 \%$ & $46.6 \%$ & $84.6 \%$ & $16.5 \%$ & $66.0 \pm 12.0$ & $2.1 \pm 0.4$ & $\begin{array}{c}0.3 \\
\text { (median) }\end{array}$ & $\begin{array}{c}\text { All-cause } \\
\text { mortality } \\
\text { Total CVD } \\
\text { events }\end{array}$ \\
\hline Zhang 2017 & China & $\mathrm{HD}$ & 414 & $61.6 \%$ & $22.9 \%$ & $94.0 \%$ & $9.2 \%$ & $\begin{array}{c}61.8 \\
\text { (median) }\end{array}$ & $\begin{array}{c}1.9 \\
\text { (median) }\end{array}$ & $\begin{array}{c}26.9 \\
\text { (median) }\end{array}$ & $\begin{array}{l}\text { All-cause } \\
\text { mortality } \\
\text { CVD } \\
\text { mortality }\end{array}$ \\
\hline Gungor 2017 & Turkey & $\begin{array}{l}\text { Predialysis } \\
\text { CKD }\end{array}$ & 228 & NA & $26.3 \%$ & $23.7 \%$ & $18.9 \%$ & NA & 2.0 & NA & $\begin{array}{c}\text { Total CVD } \\
\text { events }\end{array}$ \\
\hline Keddis 2017 & US & Txp & 200 & $59.7 \%$ & $38.5 \%$ & $94.5 \%$ & $33.5 \%$ & $\begin{array}{c}53.0 \\
\text { (median) }\end{array}$ & $\begin{array}{c}2.3 \\
\text { (median) }\end{array}$ & $\begin{array}{c}27.8 \\
\text { (median) }\end{array}$ & $\begin{array}{c}\text { Total CVD } \\
\text { events }\end{array}$ \\
\hline Tuegel 2018 & US & $\begin{array}{l}\text { Predialysis } \\
\text { CKD }\end{array}$ & 883 & $56.0 \%$ & $43.0 \%$ & $87.0 \%$ & $40.0 \%$ & $57.0 \pm 15.0$ & $\begin{array}{c}3.1 \\
\text { (median) }\end{array}$ & NA & $\begin{array}{c}\text { All-cause } \\
\text { mortality } \\
\text { HF events } \\
\text { Total CVD } \\
\text { events }\end{array}$ \\
\hline Homsak 2018 & Slovenia & $\mathrm{HD}$ & 123 & $58.5 \%$ & $36.6 \%$ & $91.0 \%$ & $26.0 \%$ & $\begin{array}{c}66.0 \\
\text { (median) }\end{array}$ & $\begin{array}{c}2.3 \\
\text { (median) }\end{array}$ & $\begin{array}{c}28.0 \\
(\text { median})\end{array}$ & $\begin{array}{l}\text { All-cause } \\
\text { mortality }\end{array}$ \\
\hline Seo 2018 & Korea & $\mathrm{HD}$ & 182 & $57.7 \%$ & $56.0 \%$ & $80.8 \%$ & $14.3 \%$ & NA & $\begin{array}{c}1.7 \\
\text { (median) }\end{array}$ & $80.7 \pm 59.2$ & $\begin{array}{c}\text { All-cause } \\
\text { mortality } \\
\text { CVD } \\
\text { mortality } \\
\text { Total CVD } \\
\text { events }\end{array}$ \\
\hline Plawecki 2018 & France & $\begin{array}{l}\text { Predialysis } \\
\text { CKD }\end{array}$ & 218 & $64.0 \%$ & NA & NA & NA & $\begin{array}{c}68.3 \\
\text { (median) }\end{array}$ & $\begin{array}{c}3.0 \\
\text { (median) }\end{array}$ & $\begin{array}{c}29.5 \\
\text { (median) }\end{array}$ & $\begin{array}{c}\text { Total CVD } \\
\text { events }\end{array}$ \\
\hline Bansal 2019 & US & $\begin{array}{l}\text { Predialysis } \\
\text { CKD }\end{array}$ & 3314 & $54.0 \%$ & $47.0 \%$ & NA & $26.0 \%$ & $\begin{array}{c}57.5 \\
\text { (median) }\end{array}$ & $\begin{array}{c}7.9 \\
\text { (median) }\end{array}$ & NA & HF events \\
\hline $\begin{array}{l}\text { Lamprea- } \\
\text { Montealegre } 2019\end{array}$ & US & $\begin{array}{l}\text { Predialysis } \\
\text { CKD }\end{array}$ & 3053 & $54.8 \%$ & $48.1 \%$ & NA & $28.0 \%$ & $57.1 \pm 11.2$ & $\begin{array}{c}8.0 \\
\text { (median) }\end{array}$ & NA & AF events \\
\hline Feldreich 2019 & UK & $\mathrm{HD}$ & 183 & $45.0 \%$ & $25.0 \%$ & NA & $19.0 \%$ & $63.0 \pm 14.0$ & $\begin{array}{c}2.6 \\
\text { (median) }\end{array}$ & NA & $\begin{array}{l}\text { CVD } \\
\text { mortality }\end{array}$ \\
\hline Choi 2020 & Korea & PD & 74 & $63.5 \%$ & $28.4 \%$ & NA & $13.5 \%$ & $53.9 \pm 11.8$ & $\begin{array}{c}3.2 \\
\text { (median) }\end{array}$ & $75.0 \pm 26.6$ & $\begin{array}{c}\text { CVD } \\
\text { mortality } \\
\text { Total CVD } \\
\text { events }\end{array}$ \\
\hline Devine 2020 & UK & Txp & 367 & $63.8 \%$ & $13.6 \%$ & $80.4 \%$ & $21.8 \%$ & $\begin{array}{c}47.0 \\
\text { (median) }\end{array}$ & $\begin{array}{c}16.2 \\
\text { (median) }\end{array}$ & $\begin{array}{c}33.1 \\
(\text { median})\end{array}$ & $\begin{array}{c}\text { All-cause } \\
\text { mortality } \\
\text { CVD } \\
\text { mortality } \\
\text { Total CVD } \\
\text { events }\end{array}$ \\
\hline Wang 2020 & China & $\mathrm{HD}$ & 205 & $61.0 \%$ & NA & NA & NA & $\begin{array}{c}59 \\
\text { (median) }\end{array}$ & 3 & $\begin{array}{c}16.0 \\
\text { (median) }\end{array}$ & $\begin{array}{l}\text { All-cause } \\
\text { mortality } \\
\text { CVD } \\
\text { mortality }\end{array}$ \\
\hline
\end{tabular}

NA: not available; HD: hemodialysis; CKD: chronic kidney disease; HDF: hemodiafiltration; Txp: transplant patients; PD: peritoneal dialysis; CVD: cardiovascular disease; HF: heart failure; AF: atrial fibrillation; DM: diabetes mellitus. 


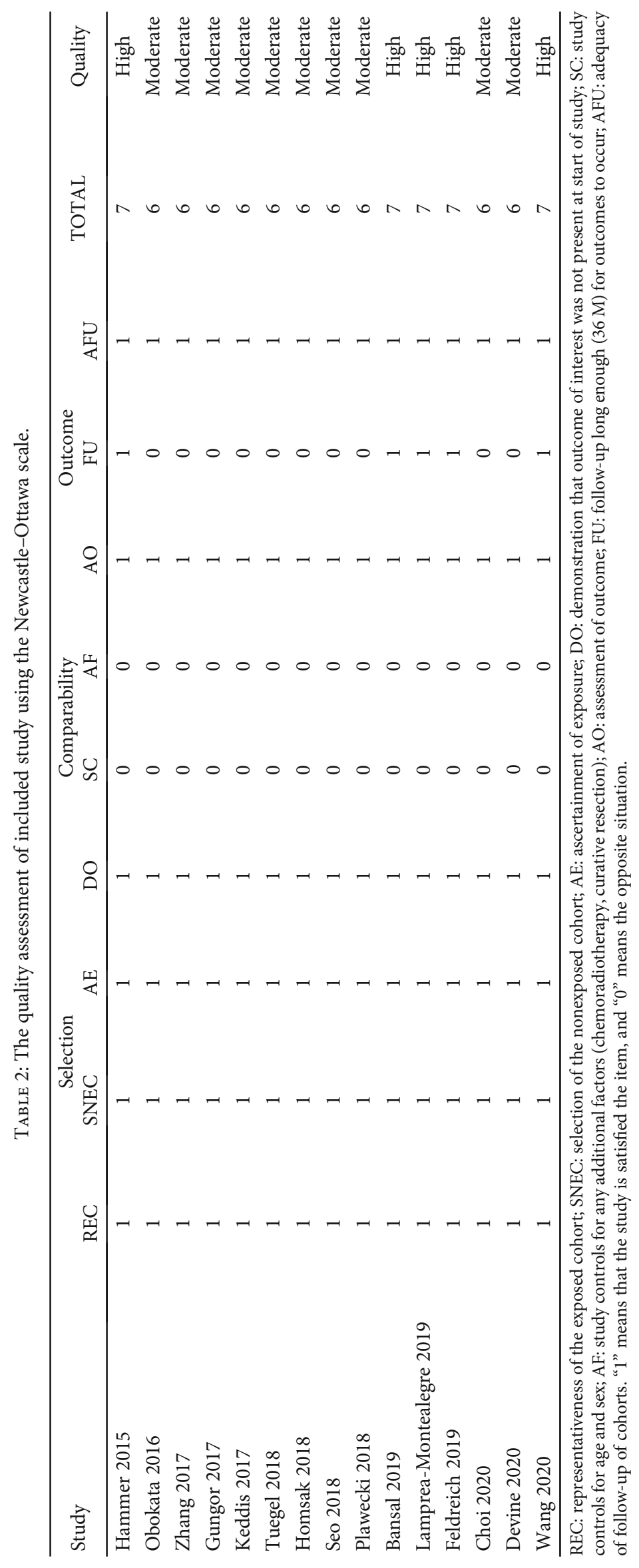




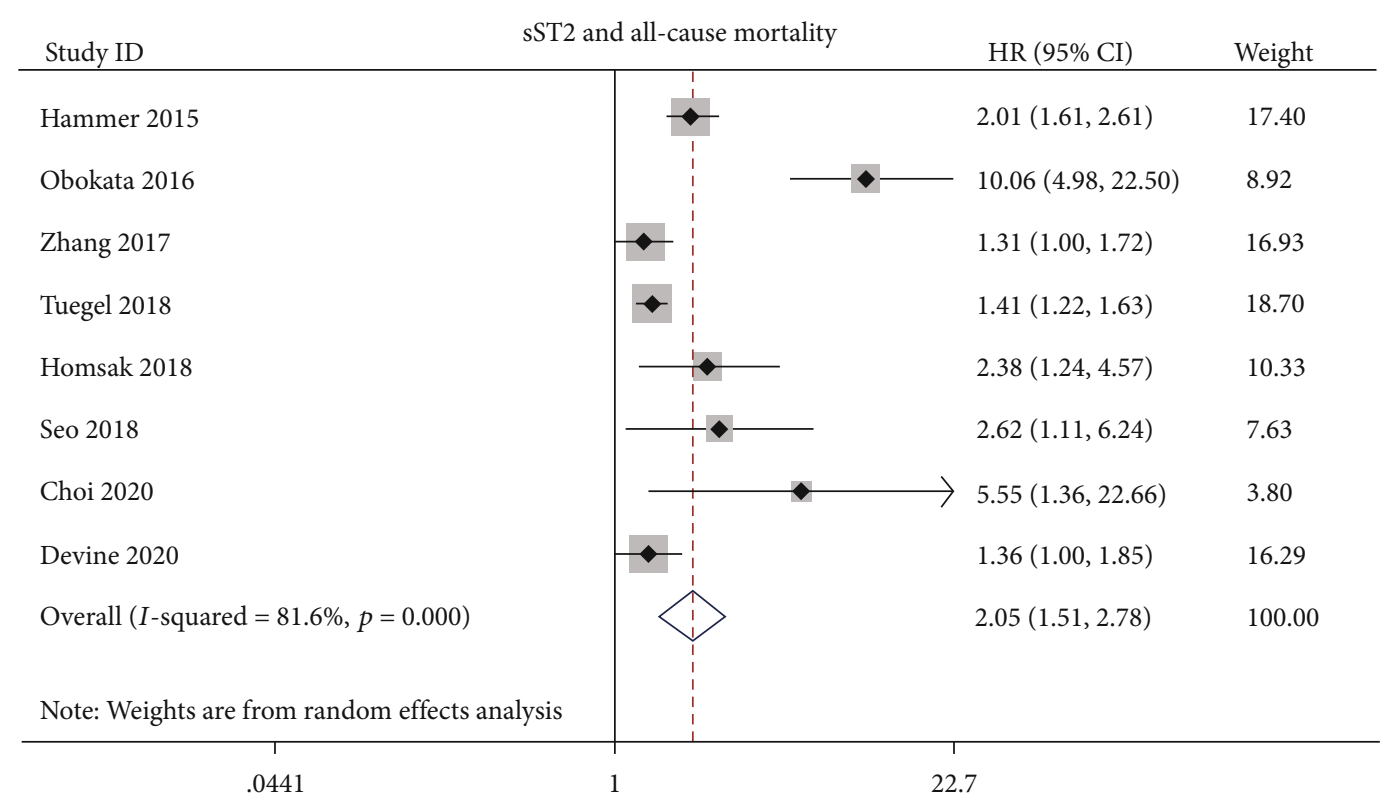

FIGURE 2: Association between sST2 and all-cause mortality in CKD patients.

TABLE 3: Subgroup analysis for the prognostic value of sST2 on all-cause mortality.

\begin{tabular}{|c|c|c|c|c|}
\hline \multirow[b]{2}{*}{ Subgroups } & \multicolumn{4}{|c|}{ All-cause mortality } \\
\hline & $N$ & HR (95\% CI) & $p$ value & $\begin{array}{c}\text { Heterogeneity } \\
I^{2}(\%), p\end{array}$ \\
\hline Overall & 8 & $2.05(1.51-2.78)$ & $<0.001$ & $81.6 \%, \leq 0.001$ \\
\hline \multicolumn{5}{|l|}{ Treatment } \\
\hline Dialysis & 6 & $2.72(1.65-4.49)$ & $\leq 0.001$ & $83.0 \%, \leq 0.001$ \\
\hline Predialysis & 1 & $1.41(1.22-1.63)$ & $\leq 0.001$ & - \\
\hline Txp & 1 & $1.36(1.00-1.85)$ & 0.050 & - \\
\hline \multicolumn{5}{|l|}{ Continent } \\
\hline Europe and America & 4 & $1.63(1.29-2.06)$ & $\leq 0.001$ & $66.4 \%, 0.038$ \\
\hline Asia & 4 & $3.53(1.17-10.66)$ & 0.025 & $89.5 \%, \leq 0.001$ \\
\hline \multicolumn{5}{|l|}{ DM proportion } \\
\hline$<$ Median percentage & 4 & $1.59(1.14-2.24)$ & 0.007 & $53.2 \%, 0.093$ \\
\hline$\geq$ Median percentage & 4 & $2.60(1.51-4.47)$ & 0.001 & $90.1 \%, \leq 0.001$ \\
\hline \multicolumn{5}{|l|}{ Sample size } \\
\hline$<400$ & 4 & $2.11(1.26-3.53)$ & 0.005 & $55.1 \%, 0.083$ \\
\hline$\geq 400$ & 4 & $2.08(1.35-3.20)$ & 0.001 & $90.4 \%, \leq 0.001$ \\
\hline
\end{tabular}

$N$, number of studies; HR: hazard ratio; CI: confidence interval; Txp: transplant patients; DM: diabetes mellitus.

rather than predialysis or transplant patients. The subgroup analysis based on continent showed that high sST2 levels could predict total CVD events for CKD patients in Asia (HR: 4.64; 95\% CI: 1.94-11.1; Table 4) rather than in Europe and America. The subgroup analysis based on DM percentage showed that high SST2 levels could predict total CVD events among the studies with DM proportion over median percentage (HR: 2.30; 95\% CI: 1.02-5.21; Table 4).

Additionally, two studies evaluated the prognostic value of sST2 for $\operatorname{HF}[20,21]$. The elevated levels of
sST2 were associated with an increased risk of HF (HR: 1.35; 95\% CI: $1.1-1.64 ; p=0.003 ; I^{2}: 43.0 \%$, $p_{\text {het }}=0.185$; Figure $4(\mathrm{~b}))$. There was only one study investigated the association between sST2 levels and the risk of atrial fibrillation (AF) among $\mathrm{CKD}$ patients. It showed that high levels of sST2 increased the risk of AF by $68 \%$ (HR: 1.68; 95\% CI: 1.09-2.58).

3.5. Publication Bias. To evaluate publication bias, Begg's and Egger's tests were performed. The result of Begg's and Egger's analysis showed there was no significant publication bias for 


\begin{tabular}{|c|c|c|c|}
\hline Study ID & VD mortality & HR ( $95 \%$ CI) & Weight \\
\hline Zhang 2017 & 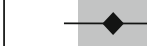 & $2.10(1.51,2.93)$ & 43.12 \\
\hline Seo 2018 & & $\Rightarrow 1.05(1.01,9.90)$ & 3.65 \\
\hline Feldreich 2019 & - & $1.63(1.13,2.35)$ & 35.45 \\
\hline Devine 2020 & $\diamond$ & $1.16(0.69,1.94)$ & 17.78 \\
\hline Overall $(I$-squared $=31.6 \%, p=0.223)$ & & $1.68(1.35,2.09)$ & 100.00 \\
\hline $\begin{array}{c}101 \\
.101\end{array}$ & & 9. & \\
\hline
\end{tabular}

(a)

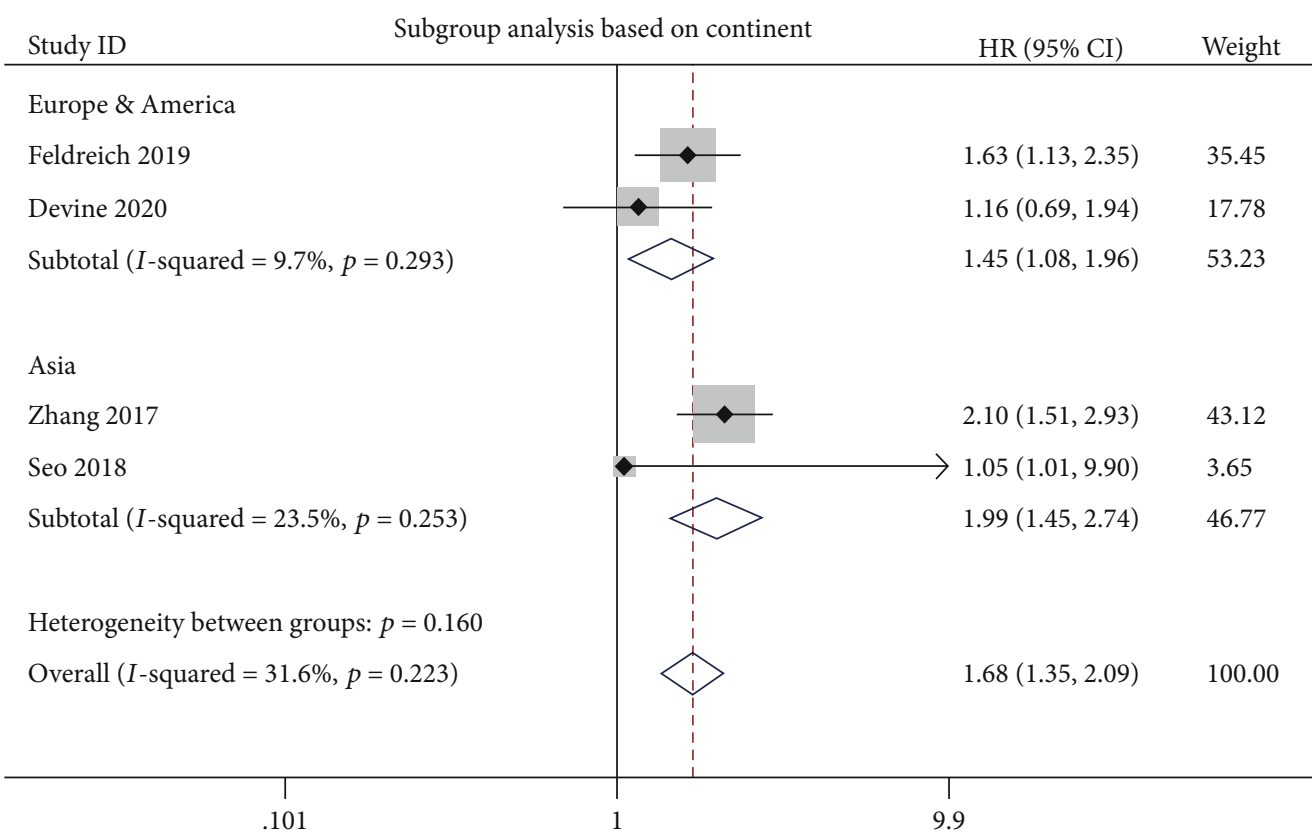

(b)

FIGURE 3: Association between sST2 and cardiovascular disease (CVD) mortality in CKD patients: (a) overall analysis; (b) subgroup analysis based on continent (Europe and America vs. Asia).

all-cause mortality $\left(p_{\text {begg's }}=0.174, p_{\text {egger's }}=0.049\right.$; Supplementary Figure 1A) and CVD mortality $\left(p_{\text {begg's }}=0.308\right.$, $p_{\text {egger's }}=0.275$; Supplementary Figure 1B).

\section{Discussion}

There were 697.5 million cases of all-stage CKD, and 1.2 million people died from CKD in 2017 Global Burden of Disease study [1]. Individuals with CKD are five to ten times more likely to die prematurely than they are to progress to ESRD [26]. The increased risk of death is mainly attributed to death from CVD $[1,2,26]$. Compared with people with normal renal function, CVD mortality is approximately $57 \%$ higher in CKD patients [27].
In MHD patients, the overall prevalence of CVD is about $71 \%$, and approximately half of deaths are attributed to CVD [28]. However, there are currently no satisfactory biomarkers on stratifying the prognosis for lifethreatening events in CKD patients. Based on such situation, it is essential to explore biomarkers that can identify high-risk patients and to eventually improve the prognosis of CKD patients. Therefore, we conducted this metaanalysis to assess sST2 in predicting all-cause mortality, CVD mortality, and CVD events among CKD patients.

\sST2 has been identified as a biomarker of cardiomyocyte hypertrophy, cardiac fibrosis, and inflammation, predicting risk of hospitalization, all-cause mortality, CVD events, and sudden death among HF and myocardial infarction patients $[4,6]$. According to the 2013 American 


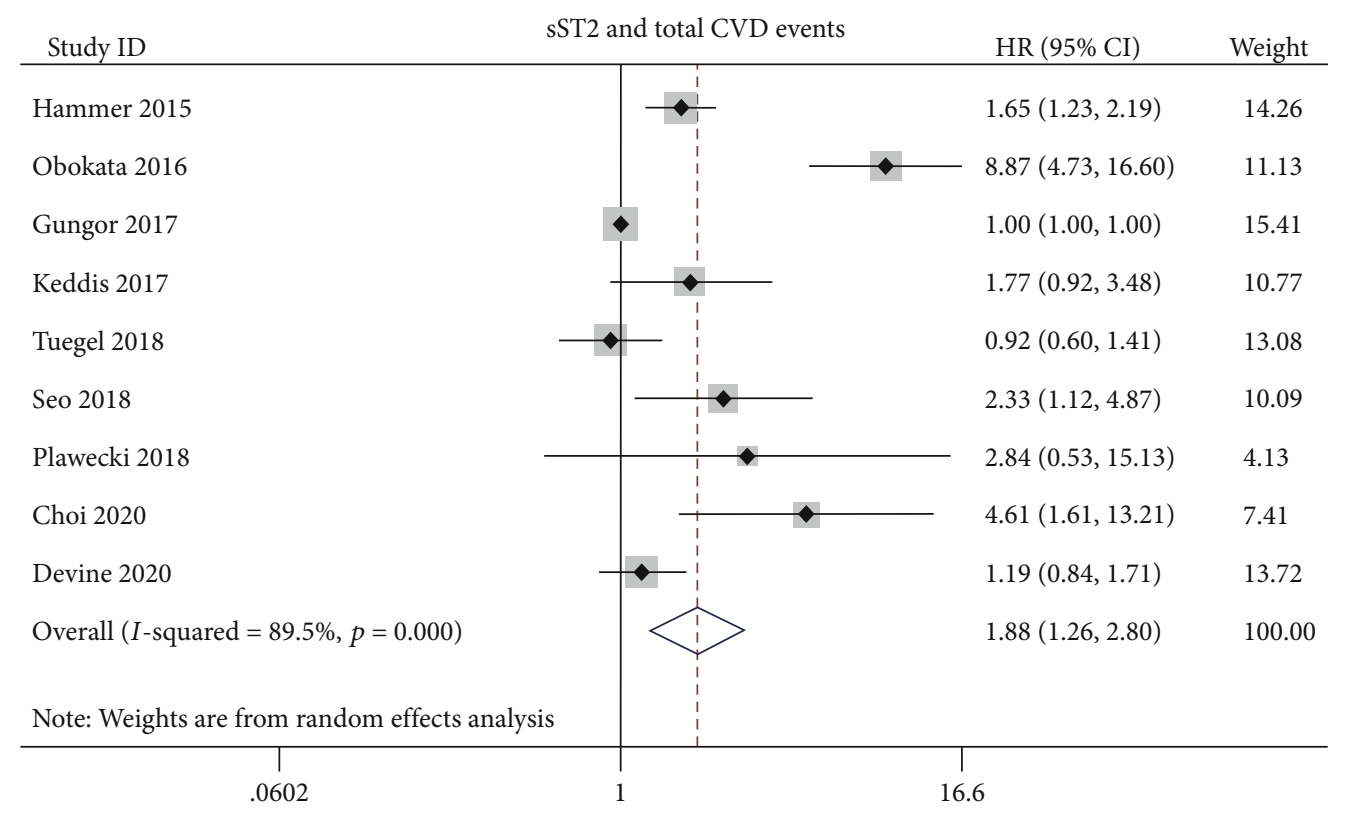

(a)

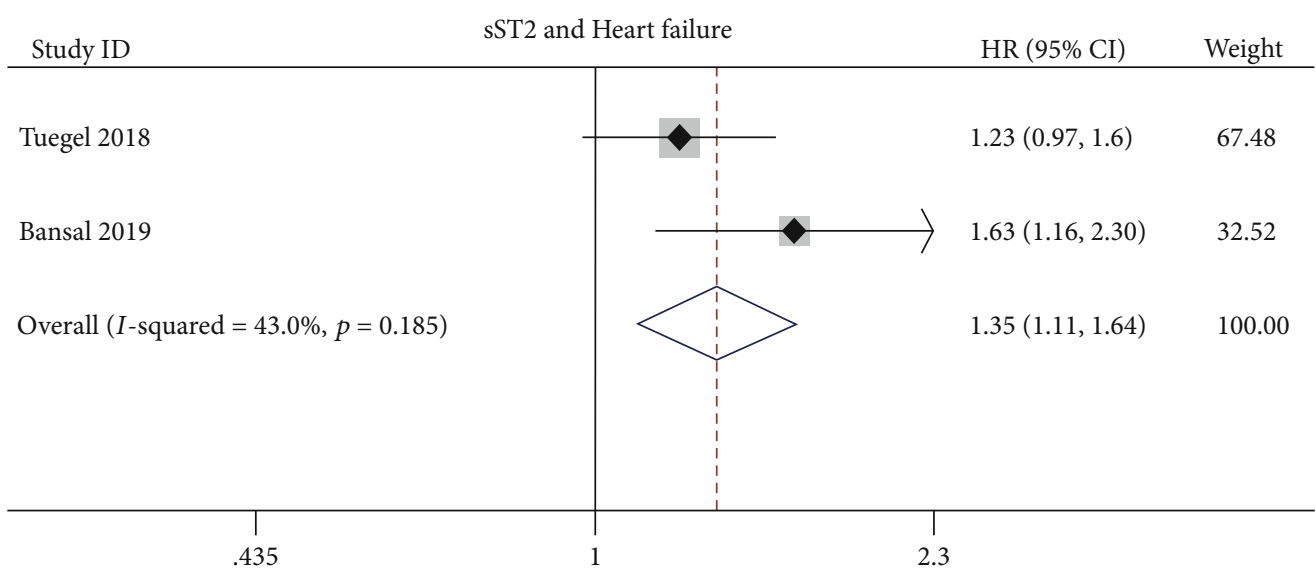

(b)

FIGURE 4: (a) Association between sST2 and total cardiovascular disease (CVD) events in CKD patients. (b) Association between sST2 and heart failure (HF) in CKD patients.

College of Cardiology Foundation/American Heart Association Guideline, sST2 was recommended as an added risk stratification factor in patients with HF [29]. Our study systematically and comprehensively evaluated the prognostic value of sST2 in CKD patients. The results of this meta-analysis revealed that elevated sST2 concentration was significantly associated with increased risk of allcause mortality. Our results are in consistent with the previous meta-analysis which reported significant link between elevated levels of sST2 and all-cause death in MHD patients after analyzing four studies [30]. Compared with this meta-analysis, our study evaluated the predictive value of sST2 levels in a larger CKD population including dialysis patients, predialysis patients, and kidney transplant patients. In addition, we also analyzed the association between sST2 levels and CVD mortality and CVD events, revealing elevated sST2 levels could predict CVD mortality and CVD events. Several studies reported that the level of
sST2 increased significantly in CKD patients and remained stable regardless of CKD stage $[4,15]$. Besides this, sST2 has low biological variability and is not disturbed by age, sex, diabetes, and dialysis [8, 16, 18, 31]. These findings further indicated that sST2 is a promising prognostic biomarker for CKD patients. Interestingly, our subgroup analysis showed a significant association between increased sST2 levels and risk of all-cause mortality, CVD mortality, and total CVD events among CKD patients from Asia, whereas patients from Europe and America showed less significant results. This difference might come from specific demographic characteristics and heterogeneity of the study population. All five Asian studies were conducted among CKD patients on dialysis, whereas all studies focused on predialysis $\mathrm{CKD}$ patients were conducted in Europe and America. Therefore, further studies on the prognosis of sST2 among predialysis CKD patients in Asia are required. 
TABLE 4: Subgroup analysis for the predictive value of sST2 on total CVD events.

\begin{tabular}{|c|c|c|c|c|}
\hline \multirow[b]{2}{*}{ Subgroups } & \multicolumn{4}{|c|}{ Total CVD events } \\
\hline & $N$ & $\operatorname{HR}(95 \% \mathrm{CI})$ & $p$ value & $\begin{array}{c}\text { Heterogeneity } \\
I^{2}(\%), p\end{array}$ \\
\hline Overall & 9 & $1.88(1.26-2.80)$ & 0.002 & $89.5 \%, \leq 0.001$ \\
\hline \multicolumn{5}{|l|}{ Treatment } \\
\hline Dialysis & 4 & $3.43(1.43-8.24)$ & 0.006 & $87.8 \%, \leq 0.001$ \\
\hline Predialysis & 3 & $1.00(1.00-1.00)$ & 0.009 & $0 \%, 0.441$ \\
\hline Txp & 2 & $1.31(0.94-1.82)$ & 0.112 & $6.1 \%, 0.302$ \\
\hline \multicolumn{5}{|l|}{ Continent } \\
\hline Europe and America & 6 & $1.23(0.96-1.59)$ & 0.107 & $70.3 \%, 0.005$ \\
\hline Asia & 3 & $4.64(1.94-11.10)$ & 0.001 & $72.8 \%, 0.025$ \\
\hline \multicolumn{5}{|l|}{ DM proportion } \\
\hline$<$ Median percentage & 4 & $1.38(0.93-2.06)$ & 0.112 & $74.5 \%, 0.008$ \\
\hline$\geq$ Median percentage & 4 & $2.30(1.02-5.21)$ & 0.046 & $91.5 \%, \leq 0.001$ \\
\hline \multicolumn{5}{|l|}{ Sample size } \\
\hline$<400$ & 6 & $1.57(1.06-2.33)$ & 0.023 & $72.7 \%, 0.003$ \\
\hline$\geq 400$ & 3 & $2.30(0.82-6.44)$ & 0.112 & $94.2 \%, \leq 0.001$ \\
\hline
\end{tabular}

CVD: cardiovascular disease; N: number of studies; HR: hazard ratio; CI: confidence interval; Txp: transplant patients; DM: diabetes mellitus.

In acute HF patients combined with renal failure, the level of sST2 was correlate positively with NT-proBNP and showed better short-term prediction outcomes than NTproBNP [32]. Among ESRD patients with elevated level of NT-proBNP, sST2 could accurately recognize individuals at high risk of CVD mortality and HF [18]. When combined multiple risk markers, sST2 improved risk stratification effectively and could better assess the adverse outcome risk both in MHD and predialysis CKD patients [8, 14, 17, 18]. Some studies have showed the relationship between elevated sST2 levels and abnormal cardiovascular function, including left ventricular diastolic dysfunction, increased cardiac remodeling, abnormal cardiac mechanics, and endothelial dysfunction which were recognized through analyzing echocardiography and brachial artery ultrasound data in ESRD patients $[15,19]$. In the future, the combination of sST2 with other markers such as NT-proBNP, cardiovascular ultrasound data may provide better prognostic value in CKD patients.

The strengths of this meta-analysis are that a number of CKD patients were included and subgroup analysis concerning multiple factors was conducted. However, there are some limitations that should be noted. First, the included studies were cohort studies. Because of its nature, this type of studies may have more confounders such as baseline patient characteristics and incomplete data collection, which might affect the stability of results. Second, although almost all HR values included are adjusted from multivariate analyses, there were still residual confounding factors cannot be excluded, and the different analyses may cause different results. Third, the pooled analysis of included studies showed high heterogeneity, and the number of included studies was small so that we could not conduct more subgroup analyses. Also, the sST2 levels varied across studies with different definition of elevation, and we could not report the boundary value in pooled studies. The retrospective nature of included studies also confers publication bias although the included studies are of high quality from NOS quality scare. Finally, the definition of CVD events in each study was inconsistent and might cause confounding bias on the pooled HR values of the risk of CVD events.

\section{Conclusion}

Our results show that high levels of sST2 could predict the all-cause mortality, CVD mortality, and CVD events in CKD patients. Larger cohort studies and researches are needed to identify high-risk individuals and explore more precise treatment in the future.

\section{Data Availability}

The data used to support the findings of this study are available from the corresponding author upon request.

\section{Conflicts of Interest}

The authors declare that there is no conflict of interest regarding the publication of this paper.

\section{Acknowledgments}

This work was supported by the National Natural Science Foundation of China (No. 81770766).

\section{Supplementary Materials}

Supplementary Figure 1: (a) Funnel plot for meta-analysis related to all-cause mortality. (b) Funnel plot for metaanalysis related to cardiovascular disease (CVD) mortality. (Supplementary Materials) 


\section{References}

[1] B. Bikbov, C. A. Purcell, A. S. Levey et al., "Global, regional, and national burden of chronic kidney disease, 1990-2017: a systematic analysis for the Global Burden of Disease Study 2017," Lancet, vol. 395, no. 10225, pp. 709-733, 2020.

[2] B. Ene-Iordache, N. Perico, B. Bikbov et al., "Chronic kidney disease and cardiovascular risk in six regions of the world (ISN-KDDC): a cross-sectional study," The Lancet Global Health, vol. 4, no. 5, pp. e307-e319, 2016.

[3] Z. J. Modi, Y. Lu, N. Ji et al., "Risk of cardiovascular disease and mortality in young adults with end-stage renal disease," JAMA Cardiology, vol. 4, no. 4, pp. 353-362, 2019.

[4] E. Homsak and D. Gruson, "Soluble ST2: a complex and diverse role in several diseases," Clinica Chimica Acta, vol. 507, pp. 75-87, 2020.

[5] S. Tominaga, "A putative protein of a growth specific cDNA from BALB/c-3T3 cells is highly similar to the extracellular portion of mouse interleukin 1 receptor," FEBS Letters, vol. 258, no. 2, pp. 301-304, 1989.

[6] M. de la Fuente, T. T. MacDonald, and M. A. Hermoso, "The IL-33/ST2 axis: role in health and disease," Cytokine \& Growth Factor Reviews, vol. 26, no. 6, pp. 615-623, 2015.

[7] T. Mueller, A. Gegenhuber, G. Kronabethleitner, I. Leitner, M. Haltmayer, and B. Dieplinger, "Plasma concentrations of novel cardiac biomarkers before and after hemodialysis session," Clinical Biochemistry, vol. 48, no. 16-17, pp. 11631166, 2015.

[8] M. Plawecki, M. Morena, N. Kuster et al., "sST2 as a new biomarker of chronic kidney disease-induced cardiac remodeling: impact on risk prediction," Mediators Inflamm, vol. 2018, article 3952526, pp. 1-9, 2018.

[9] Z. Wang, Z. Chen, H. Yu et al., "Superior prognostic value of soluble suppression of tumorigenicity 2 for the short-term mortality of maintenance hemodialysis patients compared with NT-pro BNP: a prospective cohort study," Renal Failure, vol. 482, no. 1, pp. 523-530, 2020.

[10] D. Moher, A. Liberati, J. Tetzlaff, D. G. Altman, and The PRISMA Group, "Preferred reporting items for systematic reviews and meta-analyses: the PRISMA statement," PLoS Medicine, vol. 6, no. 7, p. e1000097, 2009.

[11] "KDIGO 2017 Clinical practice guideline update for the diagnosis, evaluation, prevention, and treatment of chronic kidney disease-mineral and bone disorder (CKD-MBD)," Kidney International Supplements, vol. 7, no. 1, pp. 1-59, 2017.

[12] A. Stang, "Critical evaluation of the Newcastle-Ottawa scale for the assessment of the quality of nonrandomized studies in meta-analyses," European Journal of Epidemiology, vol. 25, no. 9, pp. 603-605, 2010.

[13] F. Hammer, B. Dieplinger, C. Drechsler et al., "Soluble ST2 predicts cardiovascular events, infectious and all-cause mortality in diabetic hemodialysis patients," European Heart Journal, vol. 36, pp. 842-843, 2015.

[14] M. Obokata, H. Sunaga, H. Ishida et al., "Independent and incremental prognostic value of novel cardiac biomarkers in chronic hemodialysis patients," American Heart Journal, vol. 179, pp. 29-41, 2016.

[15] O. Gungor, H. U. Unal, A. Guclu et al., "IL-33 and ST2 levels in chronic kidney disease: associations with inflammation, vascular abnormalities, cardiovascular events, and survival," PLoS One, vol. 12, no. 6, p. e0178939, 2017.
[16] M. T. Keddis, Z. el-Zoghby, B. Kaplan et al., "Soluble ST2 does not change cardiovascular risk prediction compared to cardiac troponin $\mathrm{T}$ in kidney transplant candidates," PLoS One, vol. 12, no. 7, p. e0181123, 2017.

[17] Z. Zhang, B. Shen, X. Cao et al., "Increased soluble suppression of tumorigenicity 2 level predicts all-cause and cardiovascular mortality in maintenance hemodialysis patients: a prospective cohort study," Blood Purification, vol. 43, no. 1-3, pp. 37-45, 2017.

[18] E. Homsak and R. Ekart, "ST2 as a novel prognostic marker in end-stage renal disease patients on hemodiafiltration," Clinica Chimica Acta, vol. 477, pp. 105-112, 2018.

[19] S. M. Seo, S. H. Kim, Y. Kim, H. E. Yoon, and S. J. Shin, "Prognostic utility of soluble suppression of tumorigenicity 2 level as a predictor of clinical outcomes in incident hemodialysis patients," International Journal of Medical Sciences, vol. 15, no. 7, pp. 730-737, 2018.

[20] C. Tuegel, R. Katz, M. Alam et al., "GDF-15, galectin 3, soluble ST2, and risk of mortality and cardiovascular events in CKD," American Journal of Kidney Diseases, vol. 72, no. 4, pp. 519528,2018

[21] N. Bansal, L. Zelnick, A. Go et al., "Cardiac biomarkers and risk of incident heart failure in chronic kidney disease: the CRIC (Chronic Renal Insufficiency Cohort) Study," Journal of the American Heart Association, vol. 8, no. 21, p. e012336, 2019.

[22] T. Feldreich, C. Nowak, T. Fall et al., "Circulating proteins as predictors of cardiovascular mortality in end-stage renal disease," Journal of Nephrology, vol. 32, no. 1, pp. 111-119, 2019.

[23] J. A. Lamprea-Montealegre, L. R. Zelnick, M. G. Shlipak et al., "Cardiac biomarkers and risk of atrial fibrillation in chronic kidney disease: The CRIC Study," Journal of the American Heart Association, vol. 8, no. 15, p. e012200, 2019.

[24] Y. B. Choi, M. J. Lee, J. T. Park et al., "Prognostic value of soluble ST2 and soluble LR11 on mortality and cardiovascular events in peritoneal dialysis patients," BMC Nephrology, vol. 21 , no. 1, p. 228, 2020.

[25] P. A. Devine, C. Cardwell, and A. P. Maxwell, "Association of soluble ST2 with all-cause and cardiovascular mortality in renal transplant recipients: a single-centre cohort study," BMC Nephrology, vol. 21, no. 1, p. 22, 2020.

[26] A. C. Webster, E. V. Nagler, R. L. Morton, and P. Masson, "Chronic kidney disease," Lancet, vol. 389, no. 10075, pp. 1238-1252, 2017.

[27] E. di Angelantonio, J. Danesh, G. Eiriksdottir, and V. Gudnason, "Renal function and risk of coronary heart disease in general populations: new prospective study and systematic review," PLoS Medicine, vol. 4, no. 9, p. e270, 2007.

[28] R. Saran, B. Robinson, K. C. Abbott et al., "US renal data system 2017 annual data report: epidemiology of kidney disease in the United States," American Journal of Kidney Diseases, vol. 71, no. 3, p. A7, 2018.

[29] C. W. Yancy, M. Jessup, B. Bozkurt et al., "2013 ACCF/AHA Guideline for the Management of Heart Failure: A Report of the American College of Cardiology Foundation/American Heart Association Task Force on Practice Guidelines," Journal of the American College of Cardiology, vol. 62, no. 16, pp. e147e239, 2013.

[30] S. Wang, F. Wei, H. Chen, Z. Wang, R. Zhang, and A. Jiang, "The prognostic value of soluble ST2 in maintenance hemodialysis patients: a meta-analysis," Blood Purification, vol. 49, no. 1-2, pp. 114-120, 2020. 
[31] N. Suthahar, L. M. G. Meems, D. J. van Veldhuisen et al., "High-sensitivity troponin-T and cardiovascular outcomes in the community: differences between women and men," Mayo Clinic Proceedings, vol. 95, no. 6, pp. 1158-1168, 2020.

[32] M. S. Kim, T. D. Jeong, S. B. Han, W. K. Min, and J. J. Kim, "Role of soluble ST2 as a prognostic marker in patients with acute heart failure and renal insufficiency," Journal of Korean Medical Science, vol. 30, no. 5, pp. 569-575, 2015. 